\title{
TEACHERS' AWARENESS OF THE BENEFITS OF CONTINUING PROFESSIONAL DEVELOPMENT
}

\section{Irina Ivanova*}

\begin{abstract}
Continuing professional development (CPD) is an essential part of teachers' professional life and an important prerequisite for high quality and sustainable development in education. However, the scope, purposes, and benefits of CPD are not always clear and straightforward to the teachers who are the primary beneficiaries of the process. In the context of the recent changes in the Bulgarian Ministry of Education policies regarding teachers' qualification and professional status, the article discusses the findings of a small-scale survey with practicing EFL teachers involved in CPD about their awareness of its nature, scope, and benefits to themselves and to their students. The survey aims to identify teachers' perceptions and beliefs about CPD, their reasons for participating in it, as well as their previous experience of CPD events.
\end{abstract}

Key words: continuing professional development, awareness, perceptions, benefits, expectations

\section{Introduction}

Continuing professional development (CPD) is a term which describes the selfdirected process of enhancing one's knowledge, skills, and expertise beyond the completion of pre-service training and education. In the context of teaching, it is beneficial for teachers themselves and for their students, as it increases and maintains the quality of tuition and improves learners' results. Hayes (2014: 5) defines CPD as a multifaceted, lifelong experience, which can take place inside or outside the workplace and which often moves beyond the professional and into the realm of a teacher's personal life too. To this definition of CPD Day (1999) adds new features, stating that it is

"the process by which, alone and with others, teachers review, renew and extend their commitment as change agents to the moral purpose of teaching; and by which they acquire and develop critically the knowledge, skills and emotional intelligence essential to good professional thinking, planning, and practice with children, young people and colleagues throughout each phase of their teaching lives" (Day 1999: 4).

\footnotetext{
* Assist. Professor PhD at Shumen University, Department of English Studies, Shumen, Bulgaria, e-mail: irina.ivanova@shu.bg.
} 
CPD involves a variety of activities ranging from formal training and development programmes for teachers to individual research or professional courses focusing on personal development. Thus, it can be adapted to teachers' needs at different phases of their career. For these reasons, the concept of CPD is widely embraced by professional associations, which see it as an important part of the working lives of their members (Friedman et al., 2000).

\section{Models of CPD}

In both academic studies and promotional literature on CPD, there are different conceptualisations and models, which largely reflect a variety of context-specific requirements and needs. They are in line with the respective fields' views of professional learning, practice, and relationships, and the ways evidence of these processes is obtained. Thus, for example, Faulkner's (1996) inputs/ outputs model is related mainly to recording and monitoring CPD, in which input is viewed as completing a certain number of learning hours or gaining learning points or credits, often through structured, formal training. The output emphasises the outcome of learning and its impact on individual practice. The sanctions model and the benefits model (Madden, Mitchell 1993) emphasise competence, which is monitored and measured by inputs, and personal benefits focused on outputs, respectively.

Kennedy (2005) identifies nine key models, which are classified in relation to their capacity for supporting professional autonomy and transformative practice. The models, called by the author training, award-bearing, deficit, cascade, standards-based, coaching/mentoring, community of practice, action research, and transformative respectively, provide a framework for analysis focused on their perceived purpose. The most widely-spread training model is characterised by a high degree of central control and standardisation often veiled as quality assurance, which overshadows the need for teachers to be proactive in identifying and meeting their own development needs. The award-bearing model of CPD emphasises the completion of award-bearing programmes of study - usually validated by universities. The deficit model addresses perceived deficits in teacher performance in an attempt to remedy perceived weaknesses in individual teachers. In the cascade model, used in situations where resources are limited, individual teachers attend training events and then disseminate the information to colleagues. The standards-based model (like its predecessor competency-based model) emphasises evidence-based, demonstrable practice, and underestimates the complex, context-specific nature of teaching. The coaching/mentoring model gives priority to various practices relying on a oneto-one relationship, where coaching is more skills based and mentoring involves an element of counseling and professional friendship. Unlike it, the community of practice model involves more than two participants and does not require the 
same confidentiality. Linked to the latter is the action research model, which is more effective when shared in communities of practice, rather than used in isolation by individual teachers. The transformative model of CPD offers a combination of practices and conditions that support proactive transformation or positive change in teachers' professional practice. The outlined models are further divided into three broader categories, namely transmission (involving the training, the award-bearing, the deficit and the cascade models), transitional (consisting of the standards-based, the coaching/mentoring, and the community of practice models) and transformative (comprising the action research and the transformative model), in terms of increasing the capacity for professional autonomy (Kennedy 2005: 248). In a later revision and update of these categories Kennedy (2014) renamed the three CPD categories into transmissive (involving training, deficit and cascade models), malleable (made up of award-bearing, standards-based, coaching/mentoring, and community of practice models), and transformative (comprising collaborative professional inquiry models), taking into account their applicability to the needs and pressures of national and local contexts in order to "challenge the dominance of the "what works' policyborrowing approach to the development of policy to promote teacher learning" (ibid: 696).

The main aim of CPD is to bring about change in the classroom practices of teachers, in their attitudes and beliefs, and in the learning outcomes of students (Guskey 2002). According to his model, a significant change in teachers' attitudes and beliefs occurs primarily after they gain evidence of improvements in student learning as a result of the changes made in their classroom practices in the form of new approaches, new materials or curricula, or a modification in teaching procedures or classroom format. The three important principles which stem from this model, and which are meant to inform planning CPD events, involve 1. recognising that change is a gradual and difficult process for teachers; 2. Ensuring that teachers receive regular feedback on student learning progress; 3. providing continued follow-up, support, and pressure (Guskey 2002: 387).

However, the implementation of CPD is not without problems. While the underlying philosophy of CPD and the differentiation of the forms it can take seem to be clear to academics and researchers, it is not so easily understood by the teachers who are its primary beneficiaries. One reason for this might be the conceptual vagueness and ambiguity in defining the nature and scope of CPD, which in turn undermine its potential value (see Friedman, Phillips 2004). If the teachers are unclear as to why they should participate in CPD, they are less likely to feel satisfied with its outcomes and less willing to incorporate the new ideas into their work. Therefore, more research is needed on the attitudes and experiences of teachers and their students. As Dadds (1997: 32) points out, "teachers and headteachers do not enter into CPD as empty vessels. They bring existing experiences, practices, perspectives, insights and, most usually, 
anxieties about the highly complex nature of their work". However, not all of them value their personal experience and expertise relying more on someone else's ideas, remedies, and solutions.

In a recent survey conducted with teachers in Saudi Arabia by Al Asmari (2016), respondents expressed their concerns about a number of issues, such as networking with colleagues, instructions from the experts, and discussion to help them in solving their classroom issues, the short duration of the CPD, and the large number of participants causing problems with the seating arrangements, among other issues needing urgent attention. These issues included concerns about institutional policies and support, indigenization of activities carried out during the CPD, and follow-up activities (ibid: 122).

\section{Background}

Although research evidence of CPD in Bulgaria was scarce and mainly anecdotal up until the 1990s, there had been some early attempts to bring about change, mainly through the British Council initiative to train teachers who would further disseminate the knowledge and experience to wider teacher audiences through locally organised training sessions, workshops, and seminars. The impact of this initial project was revised 12 years after its completion, and the results were used to determine the long-term outcomes of the programme (see Wiseman 2015). Since these first steps, CPD has been an option available to all teachers, although usually only the most motivated take part, driven by their desire to learn new things and develop professionally. In addition to this, a relatively large number of teachers attend CPD events, such as input-based training courses, as a remedial measure and a means for improvement following the inspector's or principal's recommendation.

One of the CPD schemes familiar to some of the teachers of English in Bulgaria is the British Council CPD Framework for Teachers which sees teacher development as a progression through the four stages of awareness, understanding, engagement, and integration, and the 12 professional practices and their elements. Another CPD scheme, introduced to teacher-trainees in preservice education is the European Portfolio for Student Teachers of Languages (EPOSTL) which is used to provide input and scaffold a reflective approach to teaching. The portfolio can further be used as "a means for fostering ongoing development" (Velikova 2013), although its long-term use as a tool for reflection and self-development has been questioned (ibid: 212). There are currently different training seminars offered by teacher training institutions and universities aimed at introducing and encouraging teachers to create and keep a teacher's portfolio. 
Last year, driven by the need for ongoing improvement, quality assurance and sustainability in teacher professional development, the Bulgarian Ministry of education and science issued Ordinance 12 of 1.09 .2016 on the status and the professional development of teachers, school principals and other pedagogical specialists, which outlines the standards and responsibilities of all parties working in the field of school education. This regulation defines the state educational standards for the status and professional development of teachers, directors and other pedagogical specialists in the system of pre-school and school education. The standards determine: the job description of all pedagogical specialists and the professional qualification required for this job; the conditions and procedures for organizing and conducting the practical training of traineeteachers in educational institutions; the professional qualification degrees and the way they are obtained; the procedure for receiving qualification credits; the goals, as well as the content and functions of teacher's professional portfolio.

The Ordinance made teacher ongoing qualification and CPD obligatory for all teachers, who are now subject to systematic professional attestation, which determines their professional status and affects their remuneration. According to the Ordinance, teachers are required to improve their qualifications by participating in programmes offered by approved qualification providing organizations for at least 48 academic hours for each appraisal period, and by taking part in the internal-institutional qualification in schools for no less than 16 academic hours per year.

\section{The survey}

The survey of teachers' awareness of the benefits of CPD was conducted with two groups of teachers (13 teachers from Varna region and 13 teachers from Razgrad and Ruse region) who took part in two in-service teacher training courses aimed at participants' orientation and preparation for the 5th qualification degree in Varna and Razgrad in 2017. The 5th qualification degree is the lowest in the system of teacher qualification, and by the time of applying for it teachers must have had at least 2 years of teaching experience, and are required to have done training in the Ministry approved organizations for a minimum of 16 academic hours (or 1 qualification credit) certified by a document. The 5th degree is awarded after passing an oral exam on teaching methodology for the respective subject.

The survey was conducted at the end of the training course and its purpose was presented as a general awareness inquiry into teachers' needs with the aim of planning forthcoming training events in accordance with teachers' ongoing qualification plan. Although it was anonymous, there was a personal profile section and 7 open-ended questions: 


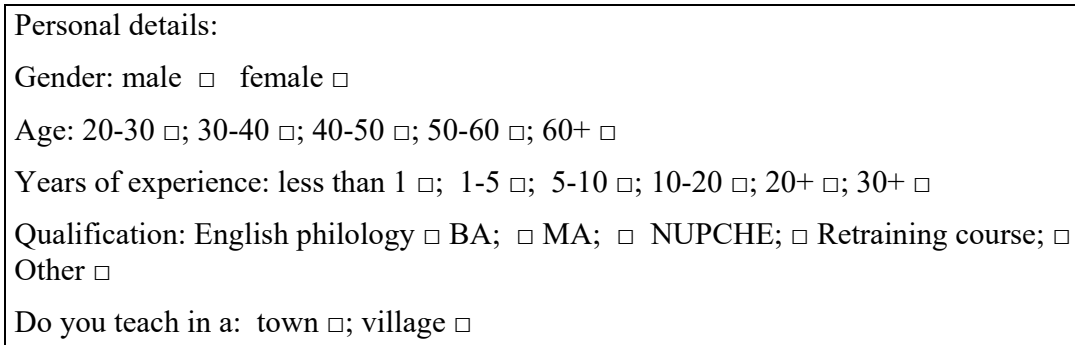

1. What does Continuing Professional Development (CPD) mean to you? What does it involve?

2. What are the potential benefits of CPD?

3. What are your reasons for wanting to acquire the 5th qualification degree?

4. Do you know what the other 4 degrees are and what they involve?

5. Are you interested in continuing your professional development? If yes, how can you do it?

6. What would be the benefits of your CPD for your students?

7. Have you taken part in the following professional development activities in the last 5 years:

Training seminars $\square$; Conferences $\square$; Qualification courses $\square$; Other $\square$

Please give more details:

The participants of both groups included 25 female teachers and 1 male teacher. The gender ratio was similar to the figures in previous research in the area (Ivanova 2015) and confirms the observation that the teaching profession is still very much female dominated.

In terms of age, about half of teachers were aged between 40 and 50 . There were no teachers older than 60 and only one teacher was younger than 30 years old.

By the time of entering formal CPD most of the teachers (about $50 \%$ ) had been in the profession for between 10 to 20 years, although in order to apply for the 5th qualification degree they only have to have 2 years of experience. This finding supports an earlier observation that a lot of teachers see CPD as an obligatory undertaking imposed by the central and local educational authorities (see fig.1).

In terms of teachers' formal qualification at the time of entering CPD, half of them had a Master's degree in English philology, or Applied linguistics. The other half had a Bachelor's degree in English philology or Primary school teaching with English (NUPCHE), and only 1 teacher was a re-trainee. 
The majority of teachers who took part in the survey work in the towns $-85 \%$, and only $15 \%$ teach in villages in the region. This shows that CPD is more accessible in larger places or places located near universities or teacher training institutions. Frequently there are only 1 or 2 English language teachers in a village school, which makes it more difficult for these teachers to participate in subject-specific CPD activities.

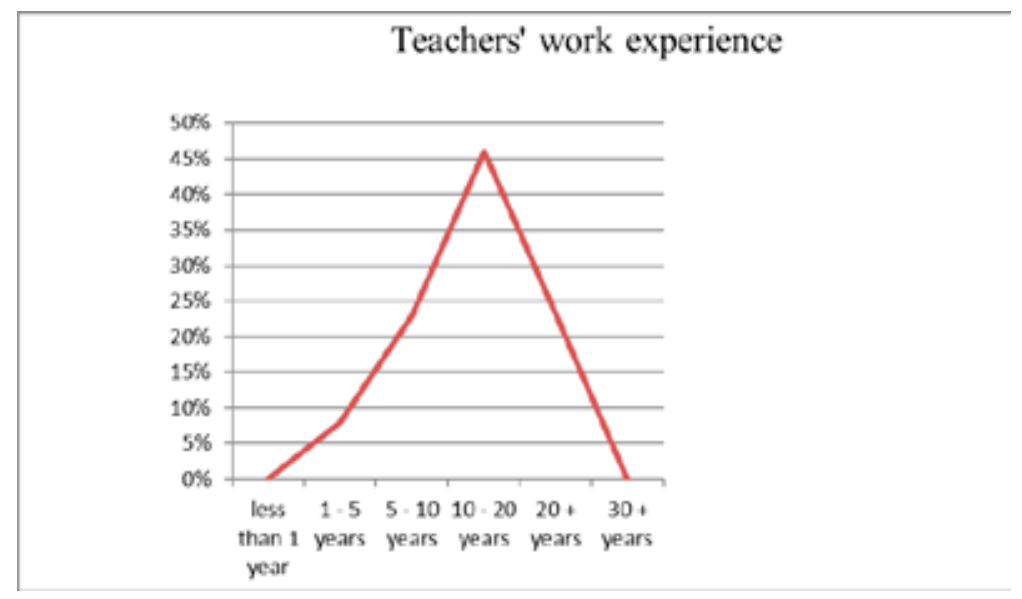

Fig.1. Teachers' work experience at the time of entering formal CPD

\section{Analysis and discussion}

The reason for choosing open ended questions for the survey was to avoid any preconceived ideas and to get a more detailed picture of teachers' experiences with CPD. In addition, by not giving participants any options or prompts to choose from, the researcher is more likely to assess how much exactly they know about the subject. As a result, most of the answers were very short, but still it was possible to detect some recurring ideas and generalisable patterns in teachers' understanding of CPD.

The first question aimed to reveal teachers' understanding of CPD and its nature and scope.

3 teachers did not answer the question, and 1 wrote that CPD is related to qualification but she is not sure what it involves. A teacher linked it to improving her English language proficiency.

Here is a sample of responses given by the teachers:

- CPD gives me new ideas about solving problems in my everyday work.

- It involves studying abroad

- It's a good way to improve/update my professional skills 
- I learn new methods of teaching

- Getting new ideas and techniques

- It means being better prepared for your students

- Better qualification

- Being informed about the latest methods and approaches

- It involves training courses and seminars to improve teaching skills

- It means constant improvement and development

- Career development

- Necessary for every teacher today

- Increasing my knowledge of language and culture

The concept of CPD which emerges from these responses can be summarised in the following key ideas:

1. CPD is seen as improvement of skills and knowledge about teaching;

2. CPD is linked to better qualification and career advancement

3. CPD takes the form of courses, seminars, and study abroad.

As it appears, a substantial part of CPD, especially its aspects related to personal initiative, self-investment, self-development and teachers' involvement in school-based communities and professional associations is missing from the responses. This finding reinforces the assumption that CPD is largely unknown and imposed top-down by educational authorities.

The second question about the benefits of CPD was not answered by 5 out of 26 teachers.

The other teachers' outlined the following potential benefits of CPD:

- improved work/ becoming a better teacher

- material benefit/bigger salary

- ability for self-assessment

- more ideas and approaches

- better lesson planning

- increased knowledge and motivation

- feeling more confident

- refreshing/ brushing up theoretical knowledge 
- sharing experience

- learning how to use technology

- credits needed for promotion

In summary, the benefits are thought by teachers in terms of improved professional knowledge, teaching skills, reflection and self-assessment, material and career benefits. The idea of sharing experiences adds a new interpersonal dimension to CPD, which is a step ahead of the self-centred perception of benefits. Interestingly, the benefits of CPD are only seen from the perspective of the teachers and, as a result, there is no mention of CPD as beneficial for learners at this stage.

Teachers' reasons for aspiring for the 5th qualification degree are phrased in terms of:

- improving their teaching

- increasing their salary

- career promotion - becoming a senior teacher

- getting a better job elsewhere

- enhancing personal motivation

- adapting and becoming more flexible

- because it is obligatory.

As for the teachers' awareness of the whole system of formal qualification within CPD, half of them said that they did not know what the other qualification degrees involved. $23 \%$ of teachers had some ideas, but were not sure if they were correct, $20 \%$ knew that for the 4th degree they have to sit a written exam on a topic related to language teaching, and only $7 \%$ said they were familiar with the requirements for the other qualification degrees (see fig. 2). It is worrying that half of the teachers have embarked on a journey without knowing what lies ahead. 


\section{Teachers' familiarity with the system of qualification}

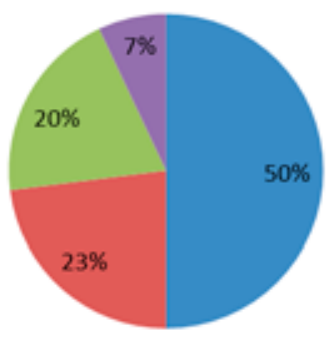

E not familiar - $50 \%$

not sure - $23 \%$

nnow about 4 th degree - $20 \%$

nnow about all degrees - $7 \%$

Fig. 2. Teachers' familiarity with the system of qualification

The 5th question was about teachers' willingness to continue their CPD further and their awareness of the ways to do it.

$20 \%$ of the teachers said they do not intend to continue as they thought 5 th degree was enough for them, and $6 \%$ were going to retire in the near future. 15 $\%$ were not sure if they want to continue, and the remaining $65 \%$ said they were willing to continue. The potential forms of CPD the teachers mentioned were limited to the following options:

- attending courses and seminars

- doing a Master's degree

- taking part in Erasmus + projects

- doing the 4th degree in 2 years' time.

The answers show that although most teachers are willing to continue their professional development, they are not aware of the whole scope of options and events it has to offer. 


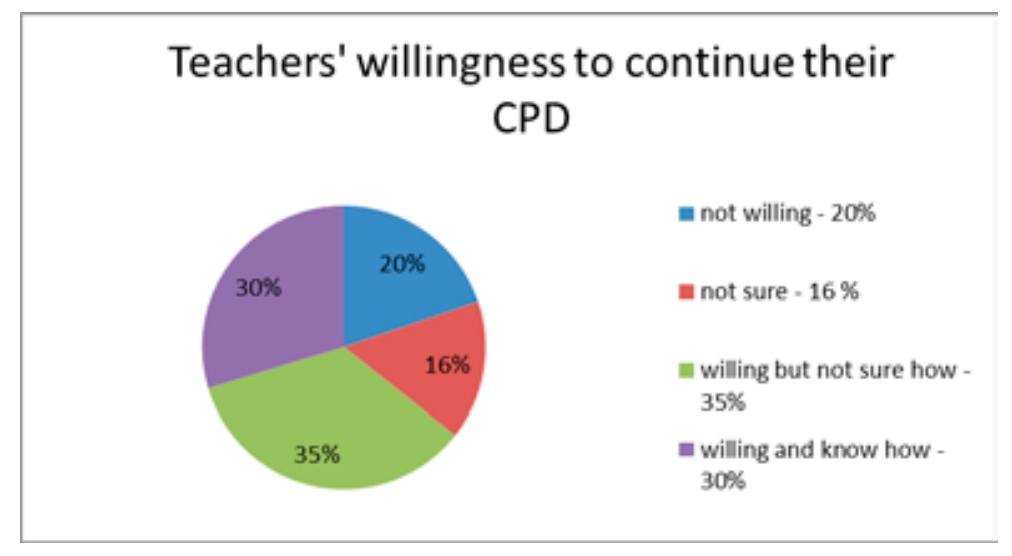

Fig.3. Teachers' willingness to continue their CPD

Question 6 drew teachers' attention to the benefits of CPD for their students.

The benefits were seen in terms of:

- students having a better-prepared teacher in terms of professional knowledge

- teachers having new ideas to motivate students and maintain their interest

- teachers using new methods and approaches

- teachers using new activities

- improved teaching.

It is not surprising that teachers see themselves as the primary beneficiaries of $\mathrm{CPD}$, and can only consider benefits for students if asked to do so. Respondents in another survey, similarly, only mentioned society or clients in passing, if at all, which is an "evidence of a tension between CPD as primarily for the benefit of the individual or employer and the principle expressed in professional codes that maintenance of competence is a professional obligation due to society" (Friedman, Phillips 2004: 369).

The last question was aimed to identify the range of CPD activities the teachers were involved in over the last 5 years.

For $29 \%$ of the teachers, the current training event was the first ever experience of CPD, which they needed in order to receive the 1 credit needed - one of the requirements for taking the 5th-degree qualification exam. The other teachers had attended from 1 to maximum 3 training seminars, usually organised by the biggest ELT materials publishers, such as Oxford, Longman, and Macmillan, or exam training seminars for Cambridge exams or IELTS preparation. The 
second most frequent provider of qualification courses were teacher training departments of universities, such as the Department for information, qualification and lifelong learning in Varna (DIQLL), part of Shumen University, for the North-East region of the country.

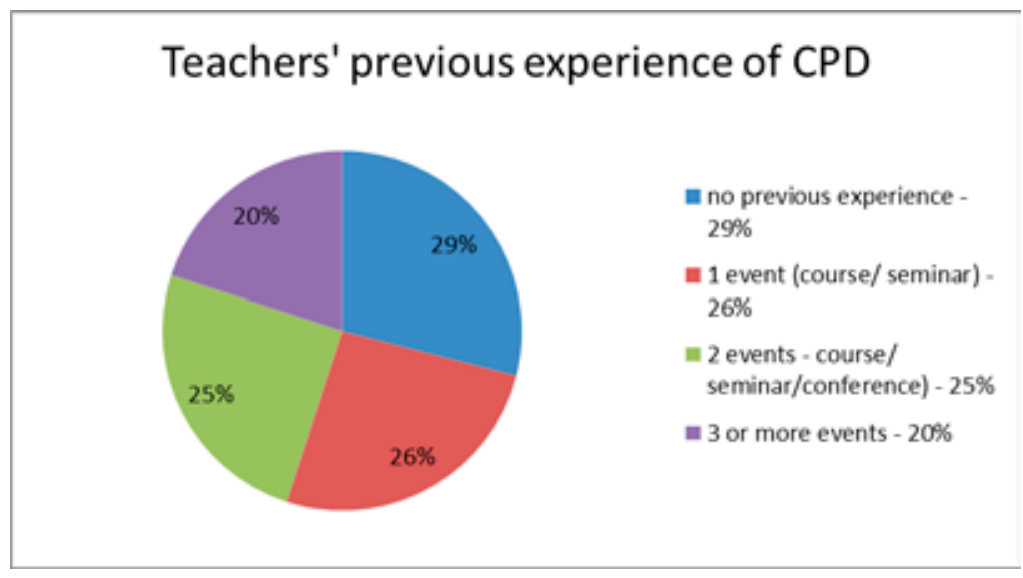

Fig. 4. Teachers' previous experience of CPD

\section{Implications and further research}

The answers to the questions show that the majority of teachers are not fully aware of the potential and the transformative power of CPD and still see it mainly as a source of new teaching ideas and skills which they can implement in their classrooms. Behind this purely pragmatic attitude, and the fact that CPD is now an integral part of their professional status lies teachers' desire to become better professionals and better teachers to their students, an intention recognised in earlier research (Fullan 1991, Huberman 1995, Guskey 2002). Becoming a better teacher is often seen as a result of a change in one's attitudes and mindset. However, in order to change their views, the teachers need to experience CPD in its full scale and, as a result, improve their teaching practices and outcomes (Harland, Kinder 1997). The model suggested by Guskey (2002), in which professional development leads to change in classroom practices, which in turn leads to change in students' learning outcomes and change in teachers' beliefs and attitudes, seems to be most relevant to the situation outlined in the survey results. If the teachers cannot see the results of their effort and time invested in CPD in the work and results of their students, they are unlikely to want to continue with it. Therefore, CPD events should target immediate, context specific problems and issues, with practical, bottom up decisions, suggested by the teachers themselves, rather than offered top down by the ministry officials, trainers, and educators. Further research is needed in the areas of assessing the changes in teachers' perceptions of CPD and their own professional growth 
as a result of being part of the process. Another important aspect is assessing the efficiency of CPD through measuring students' improvement resulting from their teachers' involvement in CPD.

\section{Conclusion}

The aim of the present small-scale survey was to investigate teachers' awareness of CPD and its benefits, as well as their willingness to invest in this ongoing process. The results of the survey show that participating teachers are not aware of the whole spectrum of activities and benefits offered by CDP. Therefore, it is necessary to find ways of raising teachers' awareness of CDP starting from preservice education and finding ways to create a sustainable model of professional learning and development which is context-specific, teacher-initiated, teachercentered and teacher-friendly. An important prerequisite for a successful incorporation of CPD into everyday school life is not simply to make CPD part of the professional accreditation process and career development, but also to increase the scope and accessibility of various CPD events, such as participation in conferences, projects, and membership in teachers' professional association. In order to make traditional CDP courses and seminars effective, their content should be based on teachers' current problems and needs.

\section{References:}

Al Asmari 2016: Al Asmari A. R. Continuous Professional Development of English Language Teachers: Perception and Practices. - Advances in Language and Literary Studies. vol. 7 No. 3, June 2016, 117-124.

British Council CPD Framework for Teachers: < https://www.teachingenglish.org.uk/ article/british-council-cpd-framework $>$. [Accessed 30 June 2017]

Dadds 1997: Dadds M. Continuing Professional Development: Nurturing the Expert Within. - Journal of In-Service Education. 23:1, 31-38.

Day 1999: Day C. Developing Teachers: The Challenges of Lifelong Learning. London: Falmer Press.

Faulkner 1996: Faulkner M. What Do We Want from CPD?. - British Journal of Administrative Management. July/August, 30-42.

Friedman et al 2000: Friedman A., Durkin C., Phillips M., K. Davis. Continuing Professional Development in the UK: Policies and Programmes. Bristol: PARN.

Friedman, Phillips 2004: Friedman A., M. Phillips. Continuing Professional Development: Developing a Vision. - Journal of Education and Work. 17:3, 361-376.

Fullan 1991: Fullan M. G. The New Meaning of Educational Change. New York: Teachers College Press.

Guskey 2002: Guskey T. R. Professional Development and Teacher Change. - Teachers and Teaching. 8:3, 381-391.

Harland, Kinder 1997: Teachers' Continuing Professional Development: Framing a Model of Outcomes. - British Journal of In-service Education. Vol. 23, No. 1, 1997, 71-84. 
Hayes 2014: Hayes D. (Ed.). Innovations in the Continuing Professional Development of English Language Teachers. British Council 2014.

Huberman 1995: Huberman M. Professional Careers and Professional Development: Some Intersections. - In Guskey T. R., M. Huberman (Eds). Professional Development in Education: New Paradigms and Practices. New York: Teachers College Press. 193224.

Ivanova 2015: Ivanova I. In-service Teachers' Problems, Needs and Expectations. - Episkop Konstantinovi Cheteniya. vol. 21. Shumen: K. Preslavsky Publishing House. 128-145.

Kennedy 2005: Kennedy A. Models of Continuing Professional Development: a Framework for Analysis. - Journal of In-service Education. vol. 31, Number 2, 235-250.

Kennedy 2014: Kennedy A. Understanding Continuing Professional Development: the Need for Theory to Impact on Policy and Practice. - Professional Development in Education. 40:5, 688-697.

Madden, Mitchell 1993: Madden C, V. Mitchell. Professions, Standards and Competence: A Survey of Continuing Education for the Professions. Bristol: University of Bristol Department for Continuing Education.

Ordinance 12 of 1.09.2016: NAREDBA № 12 ot 01.09.2016 za statuta i profesionalnoto razvitie na uchitelite, direktorite i drugite pedagogicheski spetsialisti. $<$ http://www.ittd. acad.bg/download/pks/Naredba_12.pdf $>$. [Accessed 30 June 2017].

Velikova 2013: Velikova S. Using the European Portfolio for Student Teachers of Languages (EPOSTL) to Scaffold Reflective Teacher Learning in English Language Teacher Education. - In: Edge J., S. Mann (Eds.). Innovations in Pre-Service Education and Training for English Language Teachers. British Council 2013. 201-217.

Wiseman 2015: Wiseman A. 'My Life Changed When I Saw That Notice': An Analysis of the Long-Term Impact of a Continuing Professional Development Programme in Bulgaria. - In: Hayes D. (Ed.). Innovations in the Continuing Professional Development of English Language Teachers. British Council 2014. 301-316. 